\title{
Driver Behaviors of 112 Emergency Medical Services Personnel
}

\author{
(1) Sinan Yenal ${ }^{1}$, (1) Tuğba Gültekin ${ }^{1}$, (1) Ahu Pakdemirli² \\ 1Department of Paramedics, Health Care Services Vocational School, Dokuz Eylül University, İzmir, Turkey \\ 2Department of Physiology, Gülhane School of Medicine, University of Health Sciences Turkey, Ankara, Turkey
}

\begin{abstract}
Aim: The purpose of this study is to determine the driver behaviors of emergency health personnel driving ambulances.

Materials and Methods: This descriptive study included ambulance drivers at the İzmir 112 Emergency Medical Services Department. We prepared a questionnaire consisting of 21 items as the data collection tool in this study. Moreover, we used this questionnaire to evaluate personal information and driver behaviors. Furthermore, a researcher in our study conducted face-to-face interviews to obtain data at the ambulance stations.

Results: Altogether, $90.9 \%$ of the participants were self-confident in driving ambulances. Moreover, $88.8 \%$ of the participants followed traffic rules and $74.1 \%$ followed speed limits. In total, $55.2 \%$ of the participants previously had traffic accidents, and this ratio was lower in personnel taking 24-hour shifts.

Conclusion: We found that ambulance drivers are self-confident and follow speed limits as well as traffic rules. We also determined that approximately half of the participants previously had a traffic accident.
\end{abstract}

Keywords: Ambulance, operators, ambulance driving, behaviors

\section{Introduction}

The function of 112 Emergency Medical Services (EMS) is to provide emergency health services to patients and injured as well as delivering these persons to the hospital. For this reason, emergency ambulance operation constitutes an important part of delivering EMS to patients. In Turkey, drivers, Emergency Medical Technicians (EMT) and paramedics assume the duty of ambulance drivers as part of 112 EMS (1). Ambulance drivers assume great responsibilities to protect the lives and property of patients, other ambulance personnel, and other drivers and pedestrians in traffic. The smallest mistake while driving in traffic can pose a great risk for the life of everyone in the ambulance (2). However, driving the ambulance is not the only task of the personnel who assumes this duty. In addition, these personnel also take part in the emergency care of patients and injured when they arrive at the scene (1).

Ambulance driving is dangerous and has certain identified risks $(3,4)$. One of these risks is ambulance accidents. High speed and aggressive driving style are the main risk factors for serious traffic accidents (5). Motor-vehicle death rate for emergency medical personnel is 4 times higher than other occupational groups (6). For this reason, health personnel driving ambulances work under tremendous stress. It is important to determine the driver behavior of emergency medical personnel driving ambulances under stress. This study was carried out to determine the driver behavior of emergency medical personnel driving ambulances.

\section{Materials and Methods}

This descriptive study was conducted on medical personnel (drivers, EMTs, and paramedics) assigned for duty as ambulance drivers at the Izmir 112 EMS Department.

Based on similar studies in the literature, a questionnaire consisting of 21 items was created as a data collection tool. This form was used to evaluate personal information as well as driver behavior. 
Data was obtained by the researcher through face-to-face interviews conducted at 112 ambulance stations in JanuaryFebruary 2020. Sample selection was not performed and the entire population was reached. Those who refused to participate in the study and those who were not present at 112 ambulance stations at the time of the study were excluded. Participants were informed about the study and volunteers were included in the study. Written consent was obtained from all volunteering participants. Study data were obtained by reaching a total of 143 people [62 (43.4\%) drivers, 43 (30.1\%) EMTs and 38 (26.6\%) paramedics] in İmir 112 EMS Department.

This study was approved by Dokuz Eylül University, Noninterventional Research Ethics Committee with date: 06.03.2019, protocol number: 4514-GOA and decision number: 2019/0537. The study was conducted in accordance with the working principles of the Helsinki Declaration.

\section{Statistical Analysis}

Data was evaluated with the "SPSS for Windows 18.0" package program. Descriptive statistics and "chi-square test" were used to evaluate data.

\section{Results}

$71.3 \%(n=102)$ of the participants were male. Mean age was $32.9 \pm 7.95$ years and the mean employment time was $8.4 \pm 6.10$ years. Ambulance driving behaviors of paramedics, EMTs, and drivers are given in Table 1. Based on participant responses, it was found that $90.9 \%(n=130)$ of the participants were selfconfident in ambulance driving, $88.8 \%(n=127)$ followed traffic rules and $74.1 \%(n=106)$ followed speed limits, and $71.8 \%(n=102)$ stated that traffic density affected driver behavior. Participants were evaluated for previous traffic accidents and $55.2 \%$ of the participants $(n=79)$ stated that they had a traffic accident with an ambulance. 86.1\% $(n=68)$ of the traffic accidents involved material damage and it was found that none of these accidents involved death.

Table 2 shows the comparison of driver behaviors between participants who previously had a traffic accident with an ambulance and participants who did not. There was no statistically significant difference in previous traffic accidents between the participants who stated that they followed traffic rules and speed limits while using an ambulance and those who did not $(p>0.05)$. On the other hand, the rate of having a traffic accident was lower in personnel working 24-hour shifts $(p=0.039)$.

When asked "Does driving an ambulance affect emergency care provided to the patient?", $27.2 \%(n=39)$ of the participants
Table 1. Driver behaviors of participants according to profession

\begin{tabular}{|c|c|c|c|c|c|c|c|c|}
\hline & \multicolumn{2}{|c|}{ Paramedic } & \multicolumn{2}{|c|}{ EMT } & \multicolumn{2}{|c|}{ Driver } & \multicolumn{2}{|c|}{ Total } \\
\hline & $\mathrm{n}$ & $\% *$ & $\mathbf{n}$ & $\%^{*}$ & $\mathbf{n}$ & $\%^{*}$ & $\mathrm{n}$ & $\% * *$ \\
\hline \multicolumn{9}{|c|}{ Are you willing to take driver shifts? } \\
\hline Yes & 17 & 18.3 & 24 & 25.8 & 52 & 55.9 & 93 & 65.1 \\
\hline No & 9 & 47.3 & 6 & 31.5 & 4 & 21.1 & 19 & 13.2 \\
\hline Undecided & 12 & 38.7 & 13 & 41.9 & 6 & 19.4 & 31 & 21.7 \\
\hline \multicolumn{9}{|c|}{ Self-confidence in driving } \\
\hline Yes & 28 & 21.6 & 40 & 30.7 & 62 & 47.7 & 130 & 90.9 \\
\hline No & 10 & 76.9 & 3 & 23.1 & 0 & 0 & 13 & 9.1 \\
\hline \multicolumn{9}{|c|}{ Do you follow speed limits when driving? } \\
\hline Yes & 31 & 29.2 & 31 & 29.2 & 44 & 41.6 & 106 & 74.1 \\
\hline No & 7 & 18.9 & 12 & 32.5 & 18 & 48.6 & 37 & 25.9 \\
\hline
\end{tabular}

Does patient condition (emergency status) affect ambulance speed?

\begin{tabular}{l|l|l|l|l|l|l|l|l|}
\hline Yes & 32 & 28.6 & 33 & 29.4 & 47 & 41.9 & 112 & 78.3 \\
\hline No & 6 & 19.4 & 10 & 32.2 & 15 & 48.4 & 31 & 21.7 \\
\hline Does using siren affect ambulance speed? \\
\begin{tabular}{l|l|l|l|l|l|l|l|l|}
\hline Yes & 22 & 25.0 & 32 & 36.4 & 34 & 38.6 & 88 & 61.5 \\
\hline No & 16 & 29.1 & 11 & 20.0 & 28 & 50.9 & 55 & 38.5 \\
\hline
\end{tabular}
\end{tabular}

Does patient behavior or behavior of patient relatives affect ambulance speed?

\begin{tabular}{|l|l|l|l|l|l|l|l|l|}
\hline Yes & 17 & 30.9 & 19 & 34.5 & 19 & 34.5 & 55 & 38.5 \\
\hline No & 21 & 23.9 & 24 & 27.3 & 43 & 48.9 & 88 & 61.5 \\
\hline Do you follow traffic rules in general? \\
\hline Yes & 35 & 27.6 & 40 & 31.5 & 52 & 40.9 & 127 & 88.8 \\
\hline No & 3 & 18.8 & 3 & 18.8 & 10 & 62.5 & 16 & 11.2 \\
\hline
\end{tabular}

Have you ever had a traffic accident with an ambulance?

\begin{tabular}{|l|l|l|l|l|l|l|l|l|}
\hline Yes & 12 & 15.1 & 24 & 30.3 & 43 & 54.4 & 79 & 55.2 \\
\hline No & 26 & 40.6 & 19 & 29.7 & 19 & 29.7 & 64 & 44.8 \\
\hline
\end{tabular}

Severity of previous traffic accident(s)

\begin{tabular}{|l|l|l|l|l|l|l|l|l|}
\hline $\begin{array}{l}\text { Material } \\
\text { damage }\end{array}$ & 10 & 14.7 & 19 & 27.9 & 39 & 57.3 & 68 & 86.1 \\
\hline Injury & 2 & 18.2 & 5 & 45.5 & 4 & 36.4 & 11 & 13.9 \\
\hline
\end{tabular}

Does driving increase your stress levels?

\begin{tabular}{|l|l|l|l|l|l|l|l|l|}
\hline Yes & 23 & 33.3 & 29 & 42.0 & 17 & 24.6 & 69 & 48.2 \\
\hline No & 15 & 20.3 & 14 & 18.9 & 45 & 60.8 & 74 & 51.8 \\
\hline
\end{tabular}

Do weather conditions affect your driving?

\begin{tabular}{|l|l|l|l|l|l|l|l|l|}
\hline Yes & 31 & 31.0 & 32 & 32.0 & 37 & 37.0 & 100 & 69.9 \\
\hline No & 7 & 16.3 & 11 & 25.6 & 25 & 58.1 & 43 & 30.1 \\
\hline
\end{tabular}

Does traffic density affect your driving?

\begin{tabular}{|l|l|l|l|l|l|l|l|l|}
\hline Yes & 32 & 31.4 & 32 & 31.4 & 38 & 37.3 & 102 & 71.8 \\
\hline No & 16 & 15.0 & 11 & 27.5 & 23 & 57.5 & 40 & 28.2 \\
\hline
\end{tabular}

Does driving at day or night affect your driving?

\begin{tabular}{|l|l|l|l|l|l|l|l|l|}
\hline Yes & 22 & 38.6 & 15 & 26.3 & 20 & 35.1 & 57 & 39.8 \\
\hline No & 16 & 18.6 & 28 & 32.6 & 42 & 48.8 & 86 & 60.2 \\
\hline
\end{tabular}

Do 24-hour shifts affect your driving?

\begin{tabular}{l|l|l|l|l|l|l|l|l|} 
Yes & 22 & 31.9 & 25 & 36.2 & 22 & 31.9 & 69 & 48.2 \\
\hline No & 16 & 21.6 & 18 & 24.3 & 40 & 54.1 & 74 & 51.8 \\
\hline
\end{tabular}
n: Number, EMT: Emergency Medical Technician
*Row percentage, **Column percentage


responded "Yes". These participants were asked to elaborate how driving an ambulance affected emergency care provided to the patient, and answers are given in Table 3. Majority of the

\begin{tabular}{|c|c|c|c|c|c|c|c|c|}
\hline & \multicolumn{8}{|c|}{ Previous traffic accidents } \\
\hline & \multicolumn{2}{|l|}{ Yes } & \multicolumn{2}{|l|}{ No } & \multicolumn{2}{|c|}{ Total } & \multirow[b]{2}{*}{$\chi^{2}$} & \multirow[b]{2}{*}{ p } \\
\hline & $\mathrm{n}$ & $\%^{*}$ & $\mathrm{n}$ & $\% *$ & $\mathrm{n}$ & $\% * *$ & & \\
\hline \multicolumn{9}{|c|}{ Willingness to take driver shifts } \\
\hline Yes & 54 & 58.0 & 39 & 42.0 & 93 & 83.0 & \multirow[t]{2}{*}{0.00} & \multirow[t]{2}{*}{0.989} \\
\hline No & 11 & 57.9 & 8 & 42.1 & 19 & 17.0 & & \\
\hline \multicolumn{9}{|c|}{ Self-confidence in driving } \\
\hline Yes & 75 & 57.7 & 55 & 42.3 & 130 & 90.9 & \multirow[t]{2}{*}{3.46} & \multirow[t]{2}{*}{0.062} \\
\hline No & 4 & 30.7 & 9 & 69.3 & 13 & 9.1 & & \\
\hline \multicolumn{9}{|c|}{ Following speed limits while driving } \\
\hline Yes & 56 & 52.8 & 50 & 47.2 & 106 & 74.1 & \multirow[t]{2}{*}{0.97} & \multirow[t]{2}{*}{0.325} \\
\hline No & 23 & 62.2 & 14 & 37.8 & 37 & 25.9 & & \\
\hline \multicolumn{9}{|c|}{ Following traffic rules in general } \\
\hline Yes & 71 & 55.9 & 56 & 44.1 & 127 & 88.8 & \multirow[t]{2}{*}{0.20} & \multirow[t]{2}{*}{0.654} \\
\hline No & 8 & 50.0 & 8 & 50.0 & 16 & 11.2 & & \\
\hline \multicolumn{9}{|c|}{ Driving increasing stress levels } \\
\hline Yes & 37 & 53.6 & 32 & 46.4 & 69 & 48.2 & \multirow[t]{2}{*}{0.14} & \multirow[t]{2}{*}{0.706} \\
\hline No & 42 & 56.8 & 32 & 43.2 & 74 & 51.8 & & \\
\hline \multicolumn{9}{|c|}{ Weather conditions affecting driving } \\
\hline Yes & 51 & 51.0 & 49 & 49.0 & 100 & 69.9 & \multirow[t]{2}{*}{2.42} & \multirow[t]{2}{*}{0.119} \\
\hline No & 28 & 65.1 & 15 & 34.9 & 43 & 30.1 & & \\
\hline \multicolumn{9}{|c|}{ Traffic density affecting driving } \\
\hline Yes & 52 & 51.0 & 50 & 49.0 & 102 & 71.8 & \multirow[t]{2}{*}{3.18} & \multirow[t]{2}{*}{0.074} \\
\hline No & 27 & 67.5 & 13 & 32.5 & 40 & 28.2 & & \\
\hline \multicolumn{9}{|c|}{ 24-hour shifts affecting driving } \\
\hline Yes & 32 & 46.3 & 37 & 53.7 & 69 & 48.2 & \multirow[t]{2}{*}{4.24} & \multirow[t]{2}{*}{0.039} \\
\hline No & 47 & 63.5 & 27 & 36.5 & 74 & 51.8 & & \\
\hline
\end{tabular}

Table 3. Reasons why ambulance driving affects emergency care given to the patient

\begin{tabular}{|l|l|l|}
\hline & \multicolumn{2}{|l|}{ Total ( $\mathbf{n}=39)$} \\
\hline $\begin{array}{l}\text { It affects care in terms of time. I cannot intervene } \\
\text { while parking the ambulance }\end{array}$ & $\mathbf{n}$ & \%* \\
\hline $\begin{array}{l}\text { I have difficulty intervening the patient because the } \\
\text { public thinks that I am the driver }\end{array}$ & 12 & 61.5 \\
\hline $\begin{array}{l}\text { I cannot provide care to the patient because of the } \\
\text { stress caused by driving the ambulance }\end{array}$ & 11 & 28.2 \\
\hline $\begin{array}{l}\text { I cannot provide care to the patient because of the } \\
\text { fatigue caused by driving the ambulance }\end{array}$ & 2 & 5.1 \\
\hline n: Number, *Row percentage & \multicolumn{2}{|l}{} \\
\hline
\end{tabular}

participants responded "It affects care in terms of time. I cannot intervene while parking the ambulance."

\section{Discussion}

The present study is important as it is one of the first studies evaluating driver behavior of emergency medical personnel driving ambulances. In the present study, the participants reported that they were self-confident in ambulance driving and followed traffic rules and speed limits. There are five training modules that must be completed by personnel working at the 112 EMS Department. One of these training modules is "Ambulance Driving Techniques Training”. All personnel assuming duty in 112 ambulances are required to complete these trainings in the first three years (7). The high level of self-confidence in ambulance driving and compliance with speed limits and traffic rules may be related to the module training taken by the personnel. In Turkey, highway traffic law gives certain rights and priorities to emergency vehicles such as ambulances and firefighters, but these vehicles are not allowed to travel at a higher speed or violate traffic rules (8). Traffic accidents with ambulances are one of the most serious occupational health risks faced by emergency medical personnel $(5,6)$. It was found that $55.2 \%$ of the drivers included in the study had a traffic accident. Türkdemir and Aysun (9) investigated ambulance accidents in Turkey between 1960 and 2002, and found that 614 ambulance accidents occurred, 477 of which involved only material damage, three people died and 367 people were injured in the accidents involving ambulances. In another study, Ekşi et al. (10) stated that ambulance accidents increased by $42.5 \%$ in Turkey over a 5 -year period, and found that $69.4 \%$ of emergency medical personnel were involved in a traffic accident. According to the New York State Department of Motor Vehicles statistics, two people are injured every day and 400 ambulance accidents happen annually. In addition, it is reported that $75 \%$ of these accidents are preventable (11). In a study on ambulance accidents involving death, Kahn et al. (12) showed that $16 \%$ of traffic accidents involving death occurred due to violations of traffic rules. In a USA Homeland Security report on the use of ambulances, it was stated that the causes of ambulance accident were related to reasons such as unnecessary acceleration, insufficient driver training, and driver fatigue/ burnout due to long working time (13). The data obtained in the present study is generally consistent with other studies.

No statistical relationship was found between being involved in a previous traffic accident and driver behavior. Interestingly, the rate of having a traffic accident was lower in medical personnel working 24-hour shifts. In their study on ambulance accidents, Ekși et al. (10) showed that there was no significant difference in gender, age, experience and professional title 
between ambulance personnel who were involved in traffic accidents and those who were not. Kahn et al. (12) reported that high-risk drivers caused more accidents involving death and previously had traffic accidents. In another study, Patterson et al. (13) found that ambulance personnel working in 24-hour shifts slept poorly and were exposed to injuries 2.3 times more compared to other personnel. In the same study, it was found that personnel working in 24-hour shifts were more fatigued. In a report prepared by Boone et al. (14), it was emphasized that long working hours and overtime should be avoided to prevent sleep disturbances. Hersman and Whitcomb (15) showed that injury, making mistakes, and poor performance were associated with fatigue. Although the present study is generally consistent with other studies, one of the intriguing findings is that previous accidents were less common among personnel working in 24hour shifts. In Turkey, medical personnel working in 112 EMS works in 24-hour shifts (one full day) and rests for 96 hours (four days). Ambulance operators are happy to work in this way, and they show resistance against change.

$27.2 \%$ of the participants stated that ambulance driving affects providing emergency care to the patient. Most common reason stated by the participants was that it took time for the driver to deal with the ambulance, and sufficient care could not be provided to the patient. To the best of our knowledge, there are no studies on this subject.

This study was carried out only in İmir 112 EMS Department; therefore, the results cannot be generalized. In addition, cross-sectional design of the study poses another limitation in explaining the cause and effect relationships.

\section{Conclusion}

In this study, which was conducted to determine the driver behavior of emergency medical personnel driving ambulances, it was found that ambulance drivers are self-confident in driving, follow speed limits and traffic rules, and traffic density affects the driver. Furthermore, the rate of having a traffic accident is lower in personnel working 24-hour shifts.

\section{Ethical Considerations}

Ethics Committee Approval: This study was approved by Dokuz Eylül University, Non-interventional Research Ethics Committee with date: 06.03.2019, protocol number: 4514-GOA and decision number: 2019/05-37. The study was conducted in accordance with the working principles of the Helsinki Declaration.

Informed Consent: Consent form was filled out by all participants.

Peer-review: Externally peer-reviewed.

\section{Author Contributions}

Surgical and Medical Practices: S.Y., T.G., A.P., Concept: S.Y., T.G., Design: S.Y., A.P., Data Collection or Processing: S.Y., Analysis or Interpretation: S.Y., T.G., Literature Search: S.Y., T.G., A.P., Writing: S.Y.

Conflict of Interest: No conflict of interest was declared by the authors.

Financial Disclosure: The authors declared that this study received no financial support.

\section{References}

1. Ministry health. Emergency health services regulation. Law no: 24046 (cited 2020 March 20) Available from: URL: https://www.mevzuat.gov.tr/ mevzuat?MevzuatNo=4798\&MevzuatTur $=7 \&$ MevzuatTertip $=5$

2. Heckman JD, Rosenthal RE, Worsing RA, McFee AS. Editors. Emergency care and transport of patients and woundes. American academy of orthopaedic surgeons. 1991:522-30.

3. Lewick NR, Swanson J. An Optimal solution for enhancing ambulance safety: implementing a driver performance feedback and monitoring device in ground emergency medical service vehicles. Annu Proc Assoc Adv Automot Med. 2005:49:35-50.

4. Albertsson P, Sundstro A. Evaluation of insight training of ambulance drivers in Sweden using DART, a new e-learning tool. Traffic injury prevention. 2011;12:621-9.

5. Graeve KD, Deroo KF, Calle PA, Vanhaute OA, Buylaert WA. How to modify the risk-taking behaviour of emergency medical services drivers? Eur J Emer Med. 2003;10:111-6.

6. Sanddal ND, Albert S, Hansen JD, Kupas DF. Contributing factors and issues associated with rural ambulance crashes: Literature review and annotated bibliography. Prehospital Emergency Care. 2008;12:257-67.

7. Ministry health. Communiqué on working procedures and principles of ambulance and emergency care technicians and emergency medical technicians. Law no: 27181 (cited 2020 March 20) Available from: URL: https://www.saglik.gov.tr/TR,11339/ambulans-ve-acil-bakim-teknikerleri-ileacil-tip-teknisyenlerinin-calisma-usul-ve-esaslarina-dair-teblig.html

8. Ministry of interior. Highway traffic law. Law no: 18195 (cited 2020 March 20) Available from: URL: https://www.kgm.gov.tr/sayfalar/kgm/sitetr/trafik/ kanunyonetmelikler.aspx

9. Türkdemir AH, Aysun A. Changes in ambulance accident in Turkey from 1960 to 2002. 1. Ambulance physicians congress. İstanbul, 2005 (cited 2020 March 20) Available from: URL: http://aht112acil.8m.net/about_5.html

10. Ekși A, Celikli S, Çatak I. Effects of the institutional structure and legislative framework on ambulance accidents in developing emergency medical services systems. Turk J Emerg Med. 2015;15:126-30.

11. New York, Department of Health, The operation of emergency medical services vehicles. (cited 2020 March 20) Available from: URL: https://www. health.ny.gov/professionals/ems/policy/00-13.htm

12. Kahn CA, Pirrallo R, Kuhn EM. Characteristics of fatal ambulance crashes in the United States: An 11-year retrospective analysis. Prehosp Emerg Care. 2001:5:261-9.

13. Patterson PD, Weaver MD, Frank RC, Warner CW, Martin-Gill C, Guyette FX, et al. Association between poor sleep, fatigue, and safety outcomes in emergency medical services providers. Prehosp Emerg Care. 2012;16:86-97.

14. Boone CM, Avery LW, Malone TB. A Research study of ambulance operations and best practice considerations for emergency medical services personnel. Department of homeland security science and technology directorate first responders group. 2014. https://www.dhs.gov/publication/ambulanceoperations-best-practice

15. Hersman DAP, Whitcomb EA. Fatigue risk management in high-risk environments: A call to action. Prehosp Emerg Care. 2018;22:1-2. 